Marcin Wasilewski*

Łódź

\title{
Geneza pojęcia edukacji liberalnej w antycznej Helladzie
}

Aby znaleźć w antycznych źródłach literackich odpowiedź na tytułowe zagadnienie, należy najpierw postawić źródłom właściwe pytania. Mianowicie winniśmy w źródłach poszukiwać odpowiedzi na powiązane z sobą wzajemnie pytania (problematykę): (2) jakich terminów (wyrażeń) języka greckiego używano dla oddania pojęcia edukacji liberalnej, (3) w jakich tekstach źródłowych (i w jakich kontekstach) występuje to pojęcie (wyrażone terminami greckimi), i wreszcie, (4) jaka jest geneza tego pojęcia. Owe adekwatne pytania zależą z kolei od tego, (1) co dziś rozumiemy pod pojęciem edukacji liberalnej ${ }^{1}$ (byśmy wiedzieli, czego w starożytnych źródłach poszu-

* Dr Marcin Wasilewski jest adiunktem w Zakładzie Pedagogiki Filozoficznej na Wydziale Nauk o Wychowaniu Uniwersytetu Łódzkiego.

${ }^{1}$ Edukacja liberalna jest współcześnie przede wszystkim realnym elementem amerykańskiego systemu szkolnictwa wyższego. Mianowicie najlepsze uczelnie w USA (a zarazem czołowe w rankingach światowych), kształcące elitę amerykańskiego społeczeństwa, oferują studentom (przed podjęciem studiów specjalistycznych, np. prawniczych) ogólne kształcenie humanistyczne w uniwersyteckich college'ach. Europejska tradycja natomiast edukację ogólnokształcącą realizuje przede wszystkim na poziomie elitarnego szkolnictwa średniego przygotowującego do podjęcia zaawansowanych studiów wyższych. Zob. A. Bloom, Umyst zamknięty. O tym, jak amerykańskie szkolnictwo wyższe zawiodło demokrację i zubożyło dusze dzisiejszych studentów, przeł. T. Bieroń, Poznań 2012, zwł. ss. 439-466. Niemniej jednak dyskutowanie edukacji liberalnej jest niezmiernie istotne także w naszych debatach nad polskim systemem edukacji i szkolnictwa wyższego. 
kiwać), a nawet ta ostatnia kwestia jest dyskusyjna i budzi spory, zwłaszcza w zakresie treści kształcenia w ramach edukacji liberalnej².

(1) Przyjmijmy za Bruce'em Kimballem następujące definicje (deskryptywne i normatywne) edukacji liberalnej, jakie pojawiły się w debatach akademickich w XIX i XX wieku:

- edukacja liberalna to wykształcenie na poziomie licencjackim (undergraduate), które nie jest ani utylitarne, ani zawodowe;

- edukacja liberalna to dobre wykształcenie na poziomie licencjackim;

- edukacja liberalna jest kształceniem klasycznym (wprowadzaniem w tradycję kulturową);

- edukacja liberalna jest kształceniem związanym z liberalizmem;

- edukacja liberalna jest edukacją, która uwalnia (liberates) lub wyzwala (frees).

Tę ostatnią definicję B. Kimball uznaje za współcześnie najbardziej relewantną. Dzisiejsze (nowoczesne) rozumienie edukacji liberalnej pozostaje w silnym związku z pojęciem wolności (freedom) i wyzwolenia (liberation) ${ }^{3}$.

(2) Polski termin 'edukacja liberalna' jest zapożyczeniem z języka angielskiego wyrażenia liberal education. Liberal education oznacza natomiast wykształcenie uzyskane studiowaniem liberal arts. $\mathrm{Z}$ kolei liberal arts jest angielskim przekładem łacińskiego wyrażenia artes liberales ${ }^{4}$. Zgodnie $\mathrm{z}$ uznanymi ustaleniami Henriego Marrou, artes liberales jest terminem, ja-

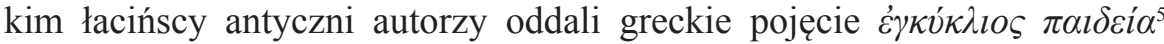
(w transliteracji: egkuklios paideia, w transkrypcji: enkyklios paideia). Graficznie ów proces językowy ująć można następująco:

${ }^{2}$ Z najnowszych sporów (z posmakiem politycznym) najgłośniejsza była bodaj polemika Marthy Nussbaum z Allanem Bloomem. A. Bloom był zwolennikiem konserwatywnej edukacji liberalnej opartej na platońskiej filozofii kształcenia i lekturze wielkich ksiąg cywilizacji Zachodu. M. Nussbaum natomiast przeciwstawiła tej koncepcji swą lewicową wizję edukacji liberalnej jako kształcenia w duchu sokratejskim, a de facto uznała za edukację liberalną kursy uniwersyteckie poświęcone problematyce tzw. mniejszości kulturowych (etnicznych, seksualnych i społecznych). Zob. A. Bloom, dz. cyt.; M. C. Nussbaum, W trosce o człowieczeństwo. Klasyczna obrona reformy ksztatcenia ogólnego, przeł. A. Męczkowska, Wrocław 2008.

${ }^{3}$ B. A. Kimball, Liberal Education, w: J. J. Chambliss (ed.), Philosophy of education. An encyclopedia, New York-London 1996, ss. 351-353.

4 Tamże, s. 353. Liberal education we współczesnej angielszczyźnie oznacza wykształcenie humanistyczne, a liberal arts to humanistyka (dosł. sztuki wyzwolone). Zob. J. LindeUsiekniewicz (red.), Wielki słownik angielsko-polski PWN-Oxford, Warszawa 2007, s. 682, sv. liberal arts i liberal education.

${ }^{5}$ H. I. Marrou, Historia wychowania w starożytności, przeł. S. Łoś, Warszawa 1969, ss. $393-394$. 
(ang.) liberal education $\leftarrow$ (ang.) liberal arts $\leftarrow$ (łac.) artes liberales $\leftarrow$

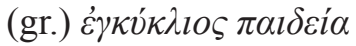

Zatem prima facie w badaniu genezy pojęcia edukacji liberalnej w antycznej Grecji powinniśmy podążać tropem terminu enkyklios paideia. W źródłach spotykamy także równoważne terminy: enkyklios paideusis, enkyklia mathemata, enkyklia paideumata ${ }^{6}$.

(3) Czym była owa antyczna enkyklios paideia? Przyjmijmy za Johannesem Christesem, że była to koncepcja edukacyjna mająca na celu rozwój osobowości młodzieży (intelektualne kształcenie oraz formowanie charakteru) poprzez niespecjalistyczne obcowanie z gramatyką, retoryką, dialektyką, arytmetyką, geometrią, astronomią i muzyką. Enkyklios paideia była propedeutyką dla zaawansowanych studiów filozoficznych, retorycznych lub specjalistycznych ${ }^{7}$.

Termin enkyklios paideia zadziwiająco późno (nawet, jeśli wziąć pod uwagę utracenie wielu źródeł z epoki hellenistycznej) pojawia się w źródłach greckich - po raz pierwszy u Dionizjusza z Halikarnasu w traktacie $O$ zestawianiu stów (Peri syntheseos onomaton), napisanym po roku 30 p.n.e. ${ }^{8}$ $\mathrm{Z}$ uwagi na skąpy materiał źródłowy z okresu hellenistycznego winniśmy także zwrócić uwagę na antyczne teksty łacińskie.

Marek Tuliusz Cyceron w swym młodzieńczym piśmie $O$ inwencji retorycznej zwraca uwagę, iż wśród argumentów wzmacniających przemówienie poświęcone konkretnej osobie należy między innymi wziąć pod uwagę, kogo ów ktoś miał za nauczyciela sztuk, które godne są wolnego człowieka (quos habuerit atrium liberalium magistros) $)^{9}$. Także w dialogu $O$ mówcy Cycerona wyrażony jest pogląd, iż nie można mówcą nazwać kogoś, kto nie jest biegły w sztukach godnych wolnego człowieka (omnibus iis artibus,

${ }^{6}$ M. Joyal, I. McDougall, J. C. Yardley (ed.), Greek and Roman education. A sourcebook, London-New York 2009, ss. 123-124; J. Christes, Enkyklios Paideia, w: H. Cancik, H. Schneider (Hrsg.), Der Neue Pauly. Enzyklopädie der Antike, Bd. 3, Stuttgart-Weimar 1997, szp. 1037.

7 Tamże, szp. 1038.

${ }^{8}$ Dion. Hal., Comp. 25. Zob. H. G. Liddel, R. Scott, Greek-English Lexicon. With a Re-

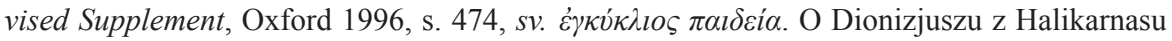
i datowaniu pisma $O$ zestawianiu stów: T. Sinko, Literatura grecka, t. 2, cz. 2: Literatura hellenistyczna (wiek I przed Chr.), Kraków 1948, ss. 81-84.

${ }^{9}$ Cic., Inv. I, 25 (35). O przenośnym znaczeniu liberalis jako tego, co godne wolnego człowieka zob. M. Plezia (red.), Słownik łacińsko-polski, t. 3, Warszawa 2007, s. 353, sv. liberalis. 
que sunt libero dignae $)^{10}$. W tym samym dialogu mamy także odwołanie (w odniesieniu do Hippiasza z Elidy) do wiedzy godnej wolnego człowieka (liberales doctrinae): geometrii, muzyki i gramatyki ${ }^{11}$. Witruwiusz w traktacie $O$ architekturze postuluje rozległą wiedzę, jaką musi opanować architekt. Jej opanowanie jest możliwe dzięki temu, że poszczególne nauki łączą się z sobą, ponieważ encyclios disciplina (tworzące krąg przedmioty kształcenia) są całością złożoną z poszczególnych częśsici ${ }^{12}$. Witruwiusz utworzył tu hybrydalną łacińską frazę, przekładając w ten sposób na łacinę grecki termin enkyklios paideia ${ }^{13}$.

Seneka w Listach moralnych do Lucyliusza twierdzi, że nazwa nauki wyzwolone (liberalia studia) oznacza, iż są to nauki godne wolnego (liber) człowieka $^{14}$. Nieco dalej Seneka zauważa, iż te nauki, które Grecy nazywają enkyklia, Rzymianie zwą liberales ${ }^{15}$ (wyzwolonymi). Kwintylian w traktacie Kształcenie mówcy pisze, że cykl nauk, jakie - zdaniem Kwintyliana - powinien opanować przyszły retor, Grecy nazywają enkyklios paideia ${ }^{16}$. Jak wynika z wywodów Kwintyliana, ma on na myśli głównie gramatykę, muzykę i geometrię ${ }^{17}$.

Z autorów greckich Pseudo-Plutarch w dialogu $O$ muzyce zalicza mousike do grona enkyklios paideia ${ }^{18}$. Chrześcijański pisarz Klemens Aleksandryjski w Kobiercach (za żydowskim filozofem Filonem z Aleksandrii) uważa enkyklia mathemata za nauki wstępne (propaideia), podrzędne wobec filozofii, tę zaś za podporządkowaną mądrości (sophia) ${ }^{19}$. Do enkyklia mathemata Klemens zalicza muzykę, geometrię, gramatykę i retorykę ${ }^{20}$ Z układu treści traktatu Sekstusa Empiryka Przeciw uczonym wynika, że do enkyklios pai-

10 Cic., De orat., I, 72.

${ }^{11}$ Cic., De orat., III, 127. Hippiasz z Elidy mógł być twórcą koncepcji edukacji matematycznej (nauczania liczenia, astronomii, geometrii i muzyki; Plat., Prot., 318 e), choć należy uwzględnić także pitagorejczyka Archytasa z Tarentu, który miał prowadzić badania peri gametrias kai arithmon kai sphairikas kai [...] peri mosikas (DK 47 B 1).

12 Vitr. I, 1, 12.

13 Zob. M. Joyal, I. McDougall, J. C. Yardley (ed.), dz. cyt., s. 206.

14 Sen., Epist., LXXXVIII, 2.

15 Sen., Epist., LXXXVIII, 23.

${ }^{16}$ Quint., Inst., I, 10, 1.

${ }^{17}$ Quint., Inst., I, 10, 1-49.

18 Plut., Mus., 1135 d.

19 Clem. Al., Strom., I, 30, 1-2.

${ }^{20}$ Clem. Al., Strom., I, 29, 10. Por. P. Hadot, Czym jest filozofia starożytna?, przeł. P. Domański, Warszawa 2000, ss. 319-320. 
deia $\mathrm{w}$ epoce grecko-rzymskiej zaliczano gramatykę, retorykę, geometrię, arytmetykę, astrologię i muzykę ${ }^{21}$. A Teon z Aleksandrii ubolewa w swych Wstępnych ćwiczeniach retorycznych, iż w jego czasach ludzie nieobeznani $\mathrm{z}$ enkyklia mathemata ośmielają się brać udział w debatach sądowych i politycznych ${ }^{22}$ (zatem retoryka jest tu także zaliczona do grona enkyklia mathemata).

Koncepcja edukacyjna enkyklios paideia obecna była nieprzerwanie w cywilizacji grecko-rzymskiej i bizantyńskiej. Jeszcze w XII wieku Anna Komnena w Aleksjadzie z dumą pisze o swoim wykształceniu w zakresie tetraktys oraz ubolewa nad brakiem należytej dbałości wśród ówczesnych elit o enkyklios paideusis ${ }^{23}$.

Ostatnią grupę przywołanych w tej sekcji źródeł, w jakich używany jest termin enkyklios paideia (i pokrewne), stanowią teksty helleńskich autorów z czasów grecko-rzymskich, w których to tekstach znajdziemy istotne z naszej perspektywy odniesienia do postaci z wcześniejszej epoki hellenistycznej. Należy jednak zauważyć, iż ci późni autorzy mogą swą własną terminologię przypisywać słynnym filozofom i historykom hellenistycznym ${ }^{24}$.

U Diogenesa Laertiosa w Żywotach i poglądach stynnych filozofów znajdziemy testimonia krytyki Diogenesa z Synopy wobec gramatyków, muzyków, matematyków i retorów ${ }^{25}$. Diogenes z Synopy w tragedii Tyestes miał także radzić zaniechanie muzyki, geometrii, astrologii i podobnych nauk (jednakże już Faworinos z Arelate wątpił w autentyczność tragedii atrybuowanych Diogenesowi) ${ }^{26}$. Diogenes Laertios przypisuje także użycie terminu enkyklia paideumata Arystypowi z Kyreny, który miał znacznie wyżej cenić filozofię, niż tego typu wykształcenie ${ }^{27}$. Zenon z Kition miał z kolei na początku swej Politei uznać enkyklios paideia za zbędną ${ }^{28}$. Nato-

${ }^{21}$ Sext. Emp., Adv. math., I-VI.

22 Theon, Prog. 1, 59.

${ }^{23}$ Ann. Comn., Alex. 1, 2; XV, 7, 9. Tetraktys w kształceniu bizantyńskim jest odpowiednikiem łacińskiego quadrivium. $\mathrm{O}$ tradycji artes liberales na łacińskim średniowiecznym Zachodzie zob. artykuł Krzysztofa Ratajczaka i zamieszczoną tam bibliografię: K. Ratajczak, Sztuki wyzwolone, w: T. Pilch (red.), Encyklopedia pedagogiczna XXI wieku, t. 6, Warszawa 2007, ss. 342-343.

\footnotetext{
${ }^{24}$ Por. J. Christes, dz. cyt., szp. 1037.

25 Diog. Laert., VI, 27-28.

26 Diog. Laert., VI, 73.

27 Diog. Laert., II, 79.

${ }^{28}$ Diog. Laert., VII, 32.
} 
miast Chryzyp z Soloi miał uznać enkyklia mathemata za bardzo pomocne ${ }^{29}$. Atenajos w Uczcie mędrców używa terminu enkyklios paideia w odniesieniu do Epikura, który miał być tego rodzaju wykształcenia pozbawiony. Filozof z Ogrodu miał także uważać, że brak paidei ułatwia studiowanie filozofii ${ }^{30}$. Plutarch w żywocie Aleksandra Wielkiego podaje, iż Filip znając naturę swego syna, nie ograniczył jego kształcenia do obcowania z muzykami i innymi nauczycielami enkyklia, lecz zaprosił słynnego Arystotelesa, by był nauczycielem Aleksandra ${ }^{31}$.

Atenajos powołując się na hellenistycznych historyków: Meneklesa z Barki i Androna z Aleksandrii (Kronika) powiada, iż mieszkańcy Aleksandrii byli nauczycielami Hellenów i barbarzyńców w okresie załamania się enkyklios paideia w burzliwym okresie rządów diadochów po śmierci Aleksandra Wielkiego. Do zasadniczej odnowy dawnej paidei miało dojść w czasach panowania Ptolemajosa Euregetesa, który sprowadził do Egiptu gramatyków, filozofów, geometrów, muzyków, malarzy, paidotrybów, lekarzy i wielu innych specjalistów (technitai) ${ }^{32}$.

(4) Dla Sekstusa Empiryka objaśnienie kwestii, skąd wywodzi się nazwa enkyklia w odniesieniu do mathemata jest zbyt oczywiste, by się nią zajmować ${ }^{33}$. Nie jest tak jednak dla nas. Wyraz enkyklia wywodzi się od homeryckiego słowa kyklos, oznaczającego 'krąg', 'koło', 'coś, co ma okrągłą formę ${ }^{34}$. Termin enkyklios oznacza 'okrągły', 'kolisty' i pojawia się w źródłach późno, po raz pierwszy jako słowo poetyckie w tragedii Eurypidesa Ifigenia w kraju Taurów w wyrażeniu enkyklioi choroi ${ }^{35}$, odnoszącym się do zataczającego kręgi w tańcu i śpiewającego pięćdziesięcioosobowego korowodu dziewcząt (Nereid).

We współczesnej literaturze przedmiotu ${ }^{36}$ spotykamy następujące hipotezy dotyczące genezy i znaczenia terminu enkyklios paideia:

29 Diog. Laert., VII, 129.

30 Athen., Deipn., XIII, 53, 588 a.

31 Plut., Alex., 7.

${ }^{32}$ Athen., Deipn., IV, 83, 184 b-c. Nie wynika z tego jednoznacznie, by Menekles i Andron wszystkie te umiejętności zaliczali do enkyklios paideia. Por. J. Christes, dz. cyt., szp. 1038.

33 Sext. Emp., Adv. math., 7.

${ }^{34}$ P. Chantraine, Dictionnare étymologique de la langue grecque. Histoire des mots,

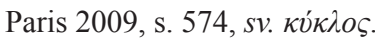

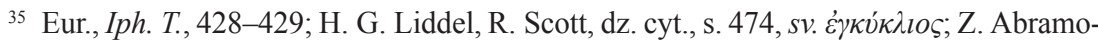

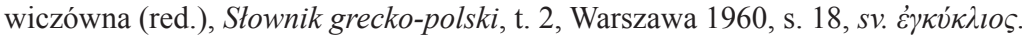

${ }^{36}$ Por. J. Christes, dz. cyt., szp. 1037-1039; M. Wesoły, Antyczna 'enkyklios paideia' 
(a) enkyklios paideia to edukacja zwykła, normalna; pierwotnie enkyklios paideia miała oznaczać wykształcenie muzyczne nabywane przez obywateli Aten, gromadzących się w kręgu przy wspólnym śpiewie i tańcu (Hermann Koller ${ }^{37}$, Harald Fuchs ${ }^{38}$, Lambertus Marie de Rijk $^{39}$ );

(b) enkyklios paideia to edukacja ogólna, niespecjalistyczna; zdobywana była $\mathrm{w}$ konfrontacji $\mathrm{z}$ kręgiem przedmiotów edukacyjnych (Friedmar Kühnert ${ }^{40}$ );

(c) enkyklios paideia to edukacja systematyczna i powszechna $\mathrm{z}$ okresu hellenistycznego; kultura powszechna (Henri-Irénée Marrou ${ }^{41}$ );

(d) enkyklios paideia to kultura kompletna mniejszości wykształconych osób i wyspecjalizowanych technitai; jest ona zintegrowanym nauczaniem wzajemnie powiązanych dyscyplin (Ilsetraut $\mathrm{Hadot}^{42}$ );

(e) enkyklios paideia to edukacja ogólna, będąca wdrożeniem do studiów wyższych i nadrzędnej mądrości; termin enkyklios paideia ma swe źródło w rozróżnieniu dokonanym przez Arystotelesa pomiędzy enkyklioi logoi (wiedzy na temat otaczającej, widzialnej przyrody) a eksoterikoi logoi (wiedzy dotyczącej archai, pryncypiów filozoficznych ,spoza” przyrody) (Abraham Bos ${ }^{43}$ ).

Należy zauważyć, że Platon (w dialogu, którego akcja umiejscowiona jest $\mathrm{w} \mathrm{V}$ wieku p.n.e.) dokonuje znamiennego rozróżnienia pomiędzy paideia i techne. Otóż istota tej dyferencjacji dotyczy tego, że paideia przysługuje człowiekowi prywatnemu (idiotes) i wolnemu (eleutheros), zaś techne jest znamienna dla człowieka pracującego dla innych (demiourgos). Tak rozu-

i potrzeba dzisiejszego krzewienia wiedzy encyklopedycznej w filozofii, w: A. Maryniarczyk, K. Stępień (red.), Spór o rozumienie filozofii, Lublin 2009, ss. 229-230.

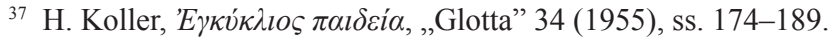

${ }^{38}$ H. Fuchs, Enkyklios Paideia, w: Reallexikon für Antike und Christentum, Bd. 9, Stuttgart 1962, szp. 369, 371.

${ }^{39}$ L. M. de Rijk, Enkyklios paideia. A study of its original meaning, ,Vivarium” 3 (1965), Ss. 24-93.

${ }^{40}$ F. Kühnert, Allgemeinbildung und Fachbildung in der Antike, Berlin 1961, s. 14.

${ }^{41}$ H. I. Marrou, dz. cyt., s. 256.

${ }^{42}$ I. Hadot, Arts libéraux et philosophie dans la pensée antique, Paris 1984, ss. 263-293 .

${ }^{43}$ A. P. Bos, Exoterikoi Logoi and Enkyklioi Logoi in the Corpus Aristotelicum and the Origin of the Idea of the Enkyklios Paideia, „Journal of the History of Ideas” 50 (1989), s. 198. 
miana paideia obejmuje kształcenie przez gramatystę, kitharystę i paidotrybę oraz - analogicznie - przez sofistę ${ }^{44}$. Rozróżnienie epi techne - epi paideia pochodzi zapewne (jak wskazuje na to testimonium platońskie ${ }^{45}$ ) od Protagorasa z Abdery, który kształcił część swych uczniów epi techne, czyli na przyszłych profesjonalistów (sofistów), a część epi paideia, tzn. dla zdobycia przez nich wykształcenia. Zatem już w V wieku p.n.e. termin paideia oznaczał kształcenie i wykształcenie, nieprzygotowujące do wykonywania płatnej profesji ${ }^{46}$. Jednakże już $\mathrm{w}$ połowie IV wieku p.n.e. sens znaczeniowy terminu paideia uległ rozszerzeniu, i obejmował także kształcenie zawodowe (handlarzy, rolników, marynarzy). Takiemu pojmowaniu paidei Platon się zdecydowanie przeciwstawial ${ }^{47}$. Jednakże twórca Akademii nie używał w ogóle w swych pismach terminu enkyklios, ani nim nie dookreślał słowa paideia ${ }^{48}$.

Termin enkyklios pojawia się natomiast (w przenośnym znaczeniu) w dwóch znamiennych kontekstach w korpusie Arystotelesowskim ${ }^{49}$. Mianowicie w piśmie $O$ niebie używa Arystoteles terminu enkyklios philosophemata $^{50}$, a w Etyce nikomachejskiej stosuje termin enkyklia w kontekście wywodów etycznych ${ }^{51}$. W obydwu tych miejscach termin enkyklios oznacza wywody nad problemami filozoficznymi i etycznymi (wypowiedzi pisemne) przeznaczone i zrozumiałe dla szerszej publiczności. To zapewne pod wpływem Arystotelesa zaczęto z czasem używać terminu enkyklios w odniesieniu do niespecjalistycznego wykształcenia.

${ }^{44}$ Plat., Prot., 312 b. Na ów passus zwrócił uwagę Kazimierz Korus, który jednak bez należytych dowodów filologicznych umiejscawia termin enkyklios paideia już w V w. p.n.e. Zob. K. Korus, Co rozumieli Ateńczycy pod pojęciem 'ogólnego wykształcenia', „Filomata” 293 (1975), s. 162.

45 Plat., Prot., 315 a.

46 Por. M. Wasilewski, Protagoras z Abdery - sofista i wychowawca. Studium z historii filozofii wychowania, Łódź 2013, ss. 215-224; tenże, Paideutyka Protagorasa i Platona, Poznań 2007, ss. 16-18.

${ }^{47}$ Plat., Leg. I, 643 d-e.

48 F. Ast, Lexicon Platonicum sive vocum Platonicarum index, Leipzig 1835, vol. 1, s. 591.

${ }^{49}$ Większość znaczeń terminu enkyklia u Stagiryty odnosi się do kolistych, okrągłych, zaokrąglonych obiektów i procesów przyrodniczych (np. ruchu, ciała). Zob. H. Bonitz, Index Aristotelicus, w: Aristotelis opera, vol. 5, Berlin 1870, s. 214, 32-42.

${ }^{50}$ Aristot., Cael., 279 a.

${ }^{51}$ Aristot., Eth. Nic., 1096 a. 
Dostrzeżony przez Platona związek między pajdeją i wolnością (zob. wyżej) został także bliżej wyeksplikowany przez Arystotelesa ${ }^{52}$. W Polityce w kontekście edukacji Stagiryta odróżnia erga (czyny, czynności) wolne (eleutheria) od niewolnych (aneleutheria). Te z technai, które szkodzą ciału, duszy lub umysłowi oraz wszelkie płatne zajęcia, jako nieprowadzące do arete, uważa Arystoteles za banauzyjskie (dosł. rzemieślnicze; niewolne, niegodne wolnego człowieka). Także zajmowanie się eleutheriai epistemai (wolnymi dziedzinami wiedzy) winno być w projektowanym przez Arystotelesa systemie edukacji ograniczone: dążenie w nich do nadmiernej doskonałości (akribeia) może przynieść szkody ${ }^{53}$. Kształcenie w wolnych przedmiotach (eleutheria paideia) jest jednym z najistotniejszych postulatów Arystotelesa w zakresie edukacji ${ }^{5}$. Znaczenie analogiczne wolności wiedzy i wolności człowieka przybliża Arystoteles w Metafizyce. Tak jak człowiek wolny (eleutheros) żyje dla siebie samego, a nie dla innych, tak też wolna wiedza (eleutheria episteme) nie jest poszukiwana dla jakiejś korzyści, lecz dla niej samej ${ }^{55}$.

Z dokonanego przeglądu i analizy źródeł antycznych wynika, iż pojęcie edukacji liberalnej ma swą genezę w dociekaniach nad pajdeją dokonywanych przez Platona i Arystotelesa w epoce klasycznej. Być może termin enkyklios paideia był stosowany już we wczesnej epoce hellenistycznej na określenie edukacji wstępnej (propaideia), niezbędnej dla rozumienia skomplikowanych zagadnień filozoficznych. Edukacja typu enkyklios paideia nie stanowiła jednak w epoce hellenistycznej i grecko-rzymskiej jakiegoś trwałego kanonu, lecz zależała od poszczególnych tradycji uprawiania filozofii i retoryki. Wynika to z faktu, iż w ogóle edukacja antyczna nie była ujęta w ramy politycznego prawodawstwa. Najistotniejsze nie są tutaj zagadnienia filologiczne, lecz doniosła koncepcja wolnej edukacji właściwej wolnemu człowiekowi ${ }^{56}$.

52 Por. B. A. Kimball, dz. cyt., ss. 353-355; A. W. Nightingale, Liberal education in Plato's 'Republic' and Aristotle's 'Politics', w: Y. L. Too (ed.), Education in Greek and Roman antiquity, Leiden-Boston-Köln 2001, ss. 133-171.

53 Aristot., Pol., VIII, 1337 b.

54 Aristot., Pol., VIII, 1338 b.

${ }_{55}$ Aristot., Metaph., I, 982 b

${ }^{56} \mathrm{~W}$ niniejszym artykule nie koncentruję się na liczbie i treści dyscyplin wchodzących w skład hellenistycznej pajdei, bo zagadnienie to jest miarodajnie wyłożone przez H. Marrou (dz. cyt.). Zauważyć jednak należy, że formalne skodyfikowanie artes liberales możliwe było dopiero w wiekach średnich, zwłaszcza na łacińskim Zachodzie, gdzie Kościół rzymski ujął $\mathrm{w}$ ramy swego prawodawstwa tworzone universitas magistrorum et scholarum. 


\section{The Genesis of the Concept of Liberal Education in Ancient Hellas (Summary)}

It results from the review and analysis of ancient sources that the concept of liberal education has its origins in the inquiries into paideia made by Plato and Aristotle in the classical period. Perhaps the term enkyklios paideia was used as early as in the Hellenistic period to determine initial education (propaideia), necessary for the understanding of complex philosophical issues. However, in the Hellenistic and GrecoRoman era, education of enkyklios paideia type did not constitute, a fixed canon, but it depended on the particular tradition of practicing philosophy and rhetoric. This is due to the fact that; in general, antique education was not incorporated into framework of political legislation. The most important issues here are not philological ones, but the significant concept of free education, typical for a free man.

Keywords: enkyklios paideia; paideia; liberal education; ancient education; Plato; Aristotle.

\section{Geneza pojęcia edukacji liberalnej w antycznej Helladzie (Streszczenie)}

Z dokonanego przeglądu i analizy źródeł antycznych wynika, iż pojęcie edukacji liberalnej ma swą genezę $\mathrm{w}$ dociekaniach nad pajdeją dokonywanych przez Platona i Arystotelesa w epoce klasycznej. Być może termin enkyklios paideia był stosowany już we wczesnej epoce hellenistycznej na określenie edukacji wstępnej (propaideia), niezbędnej dla rozumienia skomplikowanych zagadnień filozoficznych. Edukacja typu enkyklios paideia nie stanowiła jednak w epoce hellenistycznej i grecko-rzymskiej jakiegoś trwałego kanonu, lecz zależała od poszczególnych tradycji uprawiania filozofii i retoryki. Wynika to z faktu, iż w ogóle edukacja antyczna nie była ujęta $w$ ramy politycznego prawodawstwa. Najistotniejsze nie są tutaj zagadnienia filologiczne, lecz doniosła koncepcja wolnej edukacji właściwej wolnemu człowiekowi.

Słowa kluczowe: enkyklios paideia; paideia; edukacja liberalna; edukacja antyczna; Platon; Arystoteles. 